\title{
NUEVA APROXIMACIÓN AL ESTUDIO LITERARIO DE LAS JARCHAS ANDALUSÍES *
}

\author{
Por \\ MARÍA JESÚS RUBIERA MATA
}

\section{Estado de la cuestión}

Puede resultar extraño que este artículo sea una aproximación a una forma literaria cuyo contexto - la muwaššhpa - hace ya más de siglo y medio que se comenzó a estudiar (1) y cuya clave románica cumple ya cincuenta años (2), pero un repaso a la abundante bibliografía existente (3), nos muestra el enorme vacío de una aproximación realmente literaria ya que los romanistas sólo conocen la punta del iceberg, es decir las jarchas románicas (4), y los arabistas - y los hebraistas - se han dedicado especialmente a intentar resolver problemas técnicos, lo cual era por otro lado absolutamente necesario, con la única excepción de J. T. Monroe que en sus ya numerosas obras sobre las jarchas ha intentado siempre una aproximación literaria (5) en su doble vertiente de arabista y romanista. De ahí que, a partir de los hallazgos indudables de este investigador norteamericano, titulemos de "nueva" ésta

\footnotetext{
* Este trabajo ha sido realizado dentro del proyecto de investigación "Corpus historiográfic de la literatura hispano-araben.

(1) M. Hammer-Purgstalla «Notes sur Muwašsahat et Ezdjal, deux formes de poémes árabes et les Ottave rima, inventions des Arabes atribuè au italiens", Journal Asiatique, Agosto, 1839, pp. 155-173.

(2) S. M. Stern «Les vers finaux en espagnol dans las muwašahas hispano-hebraiques. Une contribuction a ' histoire de muwašsah et à l'étude du vieux dialecte espagnol mozáraben. Al-Andalus 13 (1948), 299-346.

(3) Vide M. J. Rubiera Mata Bibliografía de la literatura hispano-árabe Alicante, 1988, números 66 al 274 más apéndices.

(4) En realidad Emilio García Gómez ha publicado la traducción de la mayor parte de las jarchas andalusíes árabes, además de las romances, pero a veces escondidas en notas a pie de página como en su importante trabajo "Métrica de la moaxaja y métrica españolan Al-Andalus 39 (1974, pp. 1-259. Recientemente $F$. Corriente ha enmascarado igualmente una antología de jarchas en árabe andalusí bajo el título "Las xarajat en árabe andalusin Al-Qanțara 8 (1987), pp. 203-264.
}

(5) Vide Rubiera Bibliografia, op. cit. supra. 
nuestra aproximación, ya que partimos de una hipótesis diferente al considerar que las jarchas no son solamente un producto autóctono de Al-Andalus, hispánico y mozárabe, sino también un producto importado del resto de la Romania.

Bajo la autoridad de Ramón Menéndez Pidal los elementos románicos de la poesía hispano-árabe se han considerado exclusivamente autóctonos de Al-Andalus, es decir en clave "mozárabe» - las razones de esta teoría menéndezpiladiana ya las expuse con detalie en otro lugar (6) y no viene al caso repetirlas aquí- olvidando la otra posibilidad apuntada por Julián Ribera sobre su origen. Cito literalmente De tales antecedentes, yo creo que para explicar el origen de la lírica de Abenguzmán debe suponerse: o una lírica andaluza romanceada, anterior al siglo X, más antigua que la que aparece en los Cancioneros portugueses, o una lírica gallega antiquísima, que la colonia gallega trajo a Andalucía, de donde procede la romanceada andaluza anterior a Abenguzmán (7).

Creemos que ésta es la teoría válida hoy a partir de los descubrimientos ralizados sobre las jarchas con alguna matización. La primera el cambio de la disyuntiva "o" por la copulativa "y» y en segundo lugar que la importación lírica románica extra-andalusí no se debió exclusivamente a la colonia gallega de al-Andalus, sino también a la provenzal, como vio hace ya muchos años Emilio García Gómez - en cuanto descifró la palabra gilós - y así lo escribió:

Ni dejaría de haber relaciones entre las poesias de las diferentes comarcas románicas. En algunas jaryaas recientemente descifradas por mí y aún no publicadas - es asunto todavía oscuro - creo descubrir fenómenos lingüísticos que harian pensar en una influencia provenzal (8).

Este descubrimiento de D. Emilio fue confirmado posteriormente por el análisis lingüístico de Rafael Lapesa (9) (presencia de galoromancismos en las jarchas), por el "refrain» provenzal paralelo a una jarcha, hallado por $S$. G. Armistead (10) y por el desciframiento completo en lengua occitana, realizado por mí en la misma jarcha de Armistead (11).

La presencia de una lírica provenzal importada - en estado pre-literariono invalida la hipótesis de Ribera. La presencia "gallega" Al-Andalus, teniendo en cuenta que en este grupo se encontraban también los asturleoneses,

(6) M. J. Rubiera i Mata «Relacions d'anada i tornada entre la poesía provençal i la poesía àrab a través dels catalans: kharges en llengua occitana" Ville col.loqui internacional de llengua i literatura catalanes. Tolosa de Llenguados $12 / 17$ de Setembre de 1988 len prensal.

(7) J. Ribera y Tarragó «El Cancionero de Abenguzmán" Disertaciones y opúsculos, Madrid, 1928, pp. 53-54.

(8) E. García Gómez "La lírica hispano-árabe y la aparición de la lírica románican Al-Andalus 21 (1956) p. 311.

(9) R. Lapesa «Sobre el texto y lenguaje en algunas jarchas mozárabes" Boletín de la Real Academia Española 40 (1960), pp. 53-65.

(10) S. G. Armistead «A mozarabic harğa and a provençal refrain» Hispanic Review 41 (1973), pp. 416-417.

(11) M. J. Rubiera Mata "La lengua romance de las jarchas (Una jarcha en lengua occitanan Al-Qantara 8 (1987), pp. 319-329. 
era mayor que la provenzal - con catalanes incluidos- y cabe suponer que algunas de las jarchas presuntamente mozárabes pertenezcan en realidad a una lírica pre-literaria gallega, dados los paralelismos estilísticos encontrados desde antiguo (12), y los "galleguismos" lingüísticos descubiertos por Joan Corominas (13).

\section{Frauenlieder}

La razón de la posible existencia de tan diversos materiales poéticos respecto a su origen en las jarchas se debe a que los autores de muwaššaḥa-s no pretendían hacer una antología filológica sino recoger una copla que fuese según dice Ibn Sanācal-Mulk: picante, escabrosa, desvergonzada, es decir «muŷūn" (14) y dentro de una poética - la árabe - en la que ya en el siglo VII a los poetas no les quedaba nada por remedar) según las palabras del poeta Antara, qué mejor que glosar las Frauenlieder de la lírica románica que tenían de extraordinario, ya en principio, precisamente ser poemas femeninos, según el testimonio de Ibn Rašiq (1000-1070), señalado por Emilio García Gómez (15):

Entre los árabes es costumbre que sea el poeta el que galantee la las mujeres) y se finja muerto de amor (por ellas), mientras que entre los no árabes la costumbre es que hagan a la mujer solicitar y desear con sus declaraciones (a su amante), diferencia que constituye un indicio de la noble condición de los árabes y del celo con que guardan a sus mujeres.

Extraordinario testimonio que prueba, una vez, la existencia de una lírica europea femenina (16) y el conocimiento de la misma por los árabes, incluso por los que no eran andalusíes como es el caso de lbn Rašiq, y para los que la lengua de esta lírica no era problema y no por la vigencia de la lengua romance en al-Andalus, sino por el bilingüismo de las esclavas cantoras de origen europeo o saqāliba que creemos que son la fuente de las frauenlieder de los autores de muwaššaha-s, ya que resulta difícil suponer que los poetas árabes podían recoger estas canciones desvergonzadas de las mujeres de las tres comunidades religiosas andalusíes, cristiana, judía o musulmana, es decir de sus madres, esposas e hijas. Las qiyān o esclavas cantores que según alȲāhiḍ:

Les plus habiles d'entre elles connaissent par coeur quatre mille chansons et davantage, de deux à quatre vers, ce qui donne, sil'on fait la multiplication, une dizaine de milliers de vers dans les quels Dieu n' est cité que par inadvertance, oú le poete n'invite jamais à redouter le châtiment divin et à

(12) D. Alonso "Cancioncillas de amigo mozárabe (primavera temprana de la lirica europea)», R. F. E. (1949), pp. 297-349.

(13) J. Corominas «Para la interpretación de las jarchas recién halladas» Al-Andalus 18 (1953), pp. 140-148.

(14) E. García Gómez "Estudio del Dr at-Tirāz», preceptiva egipcia de la muwaššaha» Al-Andalus 27 (1962), p. 4.

(15) Ángel Ramírez Calvante "Jarchas, moaxajas, zéjeles (III)" Al-Andalus 41 (1976), pp. 403-404.

(16) Recordemos las obras clásicas de Alfred Jeanroy, Gastón París y Theodor Frings. 
recnercner une récompense dans l'audelà, et qui tous sont construits sur thémes de l'adultére, du proxénétisme du 'išq, de la frivolité, de la nostalgie et du désir amoureux (17).

Texto que prueba que el repertorio poético de las qiyān correspondía al de las jarchas. El origen europeo de una buena parte de estas esclavas en al-Andalus está atestiguado en multitud de lugares, pero puede servir el conocido testimonio de Muḥammad ibn al-Kattānī (m. 1029), famoso muqayyin o educador y vendedor de esclavas y autor del Kitāb at-Tašbihāt (18), colección de poemas seguramente recopilados para sus esclavas:

Soy capaz de despertar la inteligencia de las piedras y con más razón las de las personas por muy zafias e ignorantes que sean. Prueba de esto es que tengo en mi poder ahora cuatro cristianas que eran ayer ignorantes y hoy son sabias y letradas en lógica, filosofía, geometria, música, astrolabios, astronomía, gramática, prosodia, literatura y caligrafía (19).

A estos datos podemos añadir que los poetas y las qiyăn "trabajaban" conjuntamente sobre las canciones. Un testimonio antiguo: el príncipe AlMuțarrif, hijo del emir Muhammad I (852-886) se rodeó de bellas qiyān a estudiar música hasta que dominó el láud con el que se acompañaba para cantar sus poemas (20), noticia idéntica a la descubierta por Emilio García Gómez sobre Ibn Bāŷỹa (21), el cual se encerró durante años a trabajar con esclavas diestras y mezcló el canto de los cristianos con el de oriente, texto que ahora nos interesa porque parece probar que las Qiyān podían aportar también conocimientos líricomusicales no árabes.

Las qiyān se nos muestran como la fuente más probable de la materia de las jarchas de las que indudablemente no son las autoras, sino transmisoras de una poesía tradicional europea cuya feminidad originaria se expresa, en nuestra opinión, por las referencias explícitas a la corporiedad vista desde el punto de vista femenino (no me muerdas, no me toques, me haces daño, etc.), aunque indudablemente las jarchas tal y como las conocemos son obra de poetas masculinos y cultos. La pregunta a contestar es la misma que frente a la poesía femenina provenzal o de las trobairitz, es decir, cuál es la razón por la que se feminiza la poesía, por qué el yo poético masculino utiliza el lenguaje femenino (22). Ya hemos adelantado una de las razones: la búsqueda de lo muỹún como género, pero también habría que añadir otras razones como que el objeto de la pasión amorosa de la mayor parte de la poesía árabe me-

(17) No dispongo del texto árabe de la Risālat al-qiyān y utilizó la excelente traducción de Ch. Pellat «Les esclaves-chanteuses de Gahiz" Arabica 10, junio 1953, pp. 144-145.

(18) Edición de lịsăncAbbas, Beirut El Cairo 1981.

(19) Ibn Bassãm Dajira ed. IhsāñcAbbãs, Beirut, 1979, V. p. 318.

(20) Ibn Hayvăn Al-Muquabas es. M. A. Makki, Beirut, 1973, p. 205.

(21) E. García Gómez "Una extraordinaria página de Tifãsi y una hipótesis sobre el inventor del zéjel». Etudes d'Orientalisme dédiées à la mémbre de Lévi Provençal», París, 1952, II, pp. 517-523.

(22) Jean-Charles Huchet "Les trobairitz o la veu crítica» Daina 1 (València, 1986), pp. 35-69 
dieval sean los efebos y el uso del yo femenino se presente como el más adecuado para expresar la pasión homosexual, y en un segundo grado que la posición del amante en los planteamientos del amor neoplatónico o cortés árabe en que el amado es considerado como señor y el amante como su siervo, llegue a su extremo en el juego de humillación del amante/ exaltación del amado, al expresar su pasión con lenguaje femenino.

\section{Esquema de una evolución histórica}

Parece lógico suponer que los autores de muwaššaha-s buscasen la primera fuente de sus jarchas en las qiyān de origen europeo, aunque no fuese la única, pues el material no debía ser muy abundante, pues la esclava tenía que haber sido hecho prisionera suficientemente crecida para poder llegar a conocer las canciones de amor de su pueblo de origen. Sin duda los poetas recogerían igualmente otras coplas que sólo tenían de muỹūn el hecho de estar en labios femeninos, pero de un talante más casto. Nos referimos especialmente a las jarchas de tipo "cantigas de amigo", generalmente reducidas a fórmulas elocutivas (Formulaic Diction) (23) en su parte romance y en una lengua que no ofrece galleguismos ni provenzalismos, por lo que podría pertenecer a una tradición autóctona, más aun cuando la mayor parte de estas jarchas pertenecen a la serie hebrea, la etnia culturalmente más conservadora. No negamos, por tanto, la existencia de Frauenlieder en la tradición románica de Al-Andalus que coexisten en las jarchas con una lírica de importación, aún más su existencia es la única explicación posible a las jarchas en árabe andalusí que corresponden a la temática panrománica de las frauenlieder, jarchas con romancismos, jarchas con calcos tamáticos e incluso con calcos de fórmulas elocutivas como wa-ŝu nacmal, yā rabbi (24) (¿Qué haré yo, Señor?), ya que creemos con Emilio García Gómez (25) que las jarchas en árabe dialectal son una imitación de las romances.

Ahora bien la poesía tradicional femenina románica va desapareciendo de al-Andalus en la medida en que los reinos norteños cristianos se van haciendo más fuertes, con lo que disminuyen los esclavos europeos de uno y otro sexo, junto con la desromanización autóctona de al-Andalus, consecuencia de su paralela africanización surgida a partir del dominio almorávide a finales del siglo XI. Los poetas se ven obligados cada vez más a acudir a su propia inventiva con lo que las jarchas se impregnan de poética árabe hasta el punto de que en el siglo XIII las jarchas, ninguna ya en lengua románica excepto en la conservadora serie hebrea y con poetas que viven en tierras cristianas, forman ya parte de la temática de la poesía árabe.

(23) J. T. Monroe "Formulaic diction and the common origins of Romance lyric traditions» Hispanic Reviem 43 (1975), pp. 341-360.

(24) Jarcha de al-Manīši (s. XII) García Gómez Métrica, pp. cit. supra V1, 8 y F. Corriente «Las xarajāt", op. cit. supra n. ${ }^{\circ} 4$.

(25) E. García Gómez «Sobre un posible tercer tipo de poesía arábigoandaluza» Estudios dedicados a Menéndez Pidal Madrid, 1951, II, pp. 397-408. 


\section{Hacia una tipología temática}

Con estas hipótesis esbozadas en los epígrafes anteriores vamos a intentar realizar una tipología temática de las jarchas con dos consideraciones previas: las muwaššaha-s quedan absolutamente al margen porque corresponden, sin ninguna excepción, a la poética árabe como las jarchas posteriores al siglo XII, aunque tendremos que considerar algunas anteriores de tradición poética árabe, precisamente para analizar en qué se diferencian de las que corresponden a la tradición románica desde el punto de vista de su tema.

Es nuestra convición que existen tres tipos temáticos de jarchas de importación que no ofrecen ninguna duda sobre su origen: las cansons de gilós provenzales, las albadas y una cantiga de mar, estas dos últimas, gallegas.

Cansons de gilós.

Ya hemos mencionado la existencia de una jarcha que se puede leer íntegramente en lengua occitana:

Vos i entratz

cand er gilós feritz (26)

que tiene su paralelismo en un refrain provenzal en la misma koine occitana:

Quant lo gilós er fora

bels ami

vene vos a mí (27).

Hay otras dos jarchas donde aparece igualmente el "gilós" XXVIl y XXXI (28) que es sin ninguna duda la misma figura literaria de la poesía provenzal, inexistente en la poesía árabe donde se intenta asimilar a la figura del raqib, de una extensión semántica mucho más amplia en su sentido de espía o guardador (29) y que puede extenderse no sólo al marido como en su sentido provenzal sino a otros personajes del juego amroso (30). Ahora bien, mientras que el "gilós» de la primera jarcha que hemos citado corresponde exactamente a la tradición ultrapirenaica, en las otras dos, tal vez porque su lectura es difícil, el "gilós" se ha convertido en un marido calderoniano y por tanto hispánico. Nos explicaremos: el "gilós» ultrapirenaico es un personaje al que se desea la muerte, que estorba, pero al que no se le teme. Los ejemplos son muchos, por no decir todos en la poesía provenzal y en la francesa. Así algunos de los citados por Jeanroy:

(26) M. J. Rubiera "La lengua romance», op. cit. supra.

(27) Armistead "A mozarabic Harğa». op. cit. supra.

(28) La numeración corresponde a Las jarchas romances de la serie árabe en su marco de Emilio Garcia Gómez, Madrid, 1965

(29) Ibr Hazm explica quién es el raqib en El collar de la paloma Trad. Emilio García Gómez, Madrid. 1956 cam. XXVIII y no aparece el marido como raquib.

(30) El intento de sintesis hispano-árabe de G. Hilty «Celoso-Raqibn Al-Andalus 36 (1971, pp. 127-144, no es muy convincente. 
$S^{\prime}$ est drois ke jel die:

se Dieu plaist li jalos morra

si ravrai m'amie (31)

li jalous

envious

de corrous

morra (32)

Incluso el castellano (?) citado por el propio García Gómez:

Antes de tres días

morirá gelós

aprés de feria

yo me iré con vos (33)

En cambio en las dos jarchas el "gilós" es él quien amenaza con matar a los amantes. Más adelante vamos a ver ciertas matizaciones hispánicas de los temas ultrapirenaicos y esta transformación del "gilós» podría ser de la misma naturaleza, aunque la lectura difícil de estas dos jarchas tal vez podría variarse hacia una interpretación más acorde con la función actancial de la figura del personaje.

\section{Las albadas}

No es ninguna novedad señalar la presencia de albadas en las jarchas o mejor dicho de alboradas ya que no se trata de la despedida de los amantes tras la noche de amor, tema de las albas ultrapirenaicas sino del encuentro de los amantes al alba, tema de alboradas hispánicas y creemos que más concretamente galaicoportuguesas (34). El tema y el contexto lingüístico apoyan en nuestra opinión el origen foráneo de estas jarchas como la IV (anónima):
¡Alba de meu fogore!
¿Alba de meu ledore! (35)
Non estand ar-raqibe
esta nojte (ker) amore
O la VII a, b (Ibn Múallim s. X'l y anónima).

(31) Alfred Jeanroy Les origines de la poésie Iyrique en France au moyen age. París, 1969 (4 ed.) p. 78.

(32) A. Jenaroy op. cit. supra. p. 93.

(33) E. Garcia Gómez. Las jarchas romances. op. cit. supra p. 312.

(34) E. Asensio Poética y realidad en el cancionero peninsular de la Edad Media. Madrid, 1970, (2 ed.). pp. 27-28.

(35) Hemos cambiado "alma" por "alba» lectura que permite la grafia árabe y que creemos corresponde a! sentido de la alborada con un incipiente paralelismo galaicoportugués. 
Ben, ya sahhāra,

Alba q'esta con bel fogore

kand bene bide amore!

Aunque detectado el fenómeno de las diferencias entre las alboradas hispánicas y las albas ultrapirenaicas, no creemos que se haya planteado la causa del origen de esta diferencia. Apuntamos aquí la hipótesis de que podría tratarse de una diferenciación sociológica: las alboradas o encuentro al amanecer de los amantes podría corresponder a un medio rural en el que el comienzo antes del alba de las faenas agrícolas permitiese a los amantes encontrarse por ausencia del padre, el marido, etc., mientras el alba o despedida de los amantes al rayar la aurora correspondería a un ambiente urbano, la noche ciudadana encubridora, más aún cuando aparece la figura del "gaita" o centinela. Esta hipótesis avalaría nuestra opinión de ser las alboradas de las jarchas géneros de importación dado el desarrollo urbano de la civilización andalusí. Aún más la noche de amor y la despedida al alba aparece en las que creemos jarchas autóctonas en lengua "mozárabe" o en árabe dialectal como una de Ibn Baqī (s. XII) en versión de E. García Gómez (36).

Mi amigo, al alba,

se fue sin mis adioses

¿Ay qué tristeza

si en él pienso de noche!

\section{La "cantiga de mar»}

El mar no es un tema frecuente en la poesía árabe y tampoco lo es en la poesía medieval europea, excepto en la galaico portuguesa (37), considerándose incluso que la única cançon de este tipo que se encuentra en la poesía provenzal (Altes undaz que venez sur la mar), atribuída a Rimbaut de Vaqueiras o a un trovador catalán desconocido (38) es de influencia portuguesa, lengua que conocía Rimbaut de Vaquieras, autor del famoso Discort multilingüe. De ahí que consideremos la jarcha con tema de «cantiga de mar», cuyo autor es Ibn al-Labbāna de Denia (m. 1113), como correspondiente a las jarchas de importación lo que no contradice su contexto lingüístico iberorománico. Aunque no se conserva completa, ya el gusn de transición nos presenta el cuadro de las cantigas de mar con una joven llorando la ausencia del amado a la orilla del mar, más la jarcha donde también aparece el mar. La versión de Emilio García Gómez $(X X \mid X)$ es:

Ya qorazoni, ke keres bon amar

a liyorar

layta(ni obiese) weliyoš de mar.

(36) E. García Gómez "Estudio de Dār at-Tirāz" op. cit. supra p. 47.

(37) E. Asensio Poética y realidad, op. cit. supra p. 40

(38) S. Pellegrini: Studi su trove e trovatori della prima lirica portuguesa, Turín, 1937, pp. 37-39. 
Como sucede en el caso de los otros temas de importación, es rara su presencia en las jarchas en árabe dialectal, pero al menos hay una jarcha de este tema que dice en versión de Federico Corriente (39):

¿Dónde, dónde está el amado?

¡Ve con él!

ya ha cruzado los mares

¡Dios con él!

\section{La serie autóctona}

En este grupo se incluirian el resto de las jarchas, bien por motivos lingüísticos o siciológicos. Entre los primeros se encontrarían elementos que parecen corresponder a la personalidad del mozárabe, y entre los segundos elementos como la aparición de fiestas típicamente andalusíes como la Ansara o el Manraŷān, que si bien pueden ser la tradución de géneros foráneos como las mayas, no hay duda que han sido "traducidos". El intento de tipología en esta serie es una muy cautelosa aproximación, ya que en bastantes aspectos la poética árabe ha hecho su irrupción.

\section{Cantigas de amigo o de ausencia}

Conservamos el nombre clásico, pero incluimos solamente en este grupo a las jarchas "de ausencia» en la que la voz femenina se queja a sus próximos, madre, hermanas, etc., de la ausencia del amado. Generalmente los elementos románticos están reducidos a fórmulas elocutivas comunes a todas la lírica de la Romania (40), aunque creemos que no son "de importación", sino una prueba de la poligénesis de la lírica románica sobre una antañona base común. A este grupo pertenecen la mayor parte de la serie hebrea, lo que corresponde al conservadurismo de la cultura judía y en la que aparecen rasgos característicos de la misma (Aunque parezca una caricatura, sólo en la serie hebrea aparecen referencias al comercio entre todas las jarchas) (41).

\section{Jarchas de requerimiento}

Utilizamos la acepción del verbo requerir en el sentido de solitación amorosa. Son las jarchas en que el amante - no siempre la voz es femeninase dirige al amado solicitándole, con requiebros o quejas y sin terceros. Las hay romances $(I, V, V I I I, X I I, X X I I, a, b, X I I I, X X I V, X X V, X X X V I)$, pero en su mayoría están en árabe dialectal completamente o con algunos romancismos. En ellas aparecen descripciones físicas, algunos colores y los elementos obscenos. En estas jarchas la separación entre la tradición románica y la árabe

(39) F: Corriente "Las xarajat..», op. cit. supra $n .^{\circ} 77$.

(40) J. T. Monroe "Formulaic Diction. ", op. cit. supra M. Frenk Alatorre "Jarýas mozárabes y estribillos franceses» Nueva Revista de Filología Hispánica 6 (1952) pp. 281-284. M. J. Rubiera i Mata "Cançonetes de tipus kharja en la Jiteratura catalana» en Homenatje a Joan Fuster (en prensa).

141) Véase las jarchas n. ${ }^{\circ} 11,12,13$ de la serie hebrea incluidas como apéndice en Las jarchas.., op. cit. supra. 
parece confusa, porque las expresiones subidas de tono pertenecen a la poética árabe, cmo ya se ha visto desde antiguo, tanto desde la lengua (42) o desde el tema. Ya Emilio García Gómez consideró como puramente árabe la fórmula elocutiva wa-qum bi-jal jalī ilā aqrāti (une mis ajorcas con los pendientes) que se encuentra en una jarcha románica (IX), en una dialectal (43) y en la poesía en árabe clásico (44). Otro elemento autóctono sería la aparición de elementos urbanos explícitos (calles, zocos, vecinos, etc.) que dan color local andalusí a estas jarchas realmente hispano-árabes y que requieren un estudio detallado que no podemos incluir aquí.

\section{Canciones de cuna}

En el lenguaje amoroso literario, como seguramente en el real, la transposición del lenguaje materno-filial es un hecho que se puede detectar fácilmente sin necesidad de buscas antecedentes en la diosa Astarté, como quiere Monroe (45). Esta transposición aparece en las jarchas con frecuencia (el "hijo ajeno» XXVIII, por ejemplo), pero los autores de muwaššahas llegan a utilizar literalmente canciones de cuna, tema que creemos ofrece un interesante campo de investigación. Hay dos ejemplos clarísimos, ambos en árabe dialectal. Una es de al-Yazzār de Zaragoza (s. XI) y que es una nana se percibe desde el gusn de transición en el que la jarcha se pone en labios de una bella "que tenía un niño» y decía:

¿No vienen, niño mío, a mi lado?

Hoy desayunarás

Te entregaré mi hermosura,

te regalaré mi pecho

y no escatimaré (46)

Aún más sorprendente es la otra canción de cuna que se encuentra dentro de una muwaššaha de tema religioso, un poema "expiratorio» que estudió Emilio García Gómez (47) y cuya versión española reproducimos aquí:

Mi pequeñín, que no duerme y me llora clama,

tiene hambre el pobre y me grita: ¡Señora mamá!

(42) L. Peirone "Observazioni sulla khargia mozarabica" Giornale Italiano de Filologia 2 (7958), pp. 295-303.

(43) E. García Gómez "Estudio de Dār at-Tirāz.n op. cit. supra n. ${ }^{\circ} 13$.

(44) E. García Gómez "Veinticuatro jarỹas romances en muwašsaHas árabes» Al-Andalus 18 (1952) pp. $91-92$.

(45) J. T. Monroe "Estudios sobre las jarchas; las jarchas y la poesía popular norteafricana» Nueva Revista de Filología Hispánica 25 (1976), pp. 1-16.

(46) Se encuentra en la muwaššaha no 117 del Y̧ays at-tawš̉̆ de lbn al-Jațīb. E. Garcia Gómez «métrica..», op. cit. supra al V. B. F. Corriente "las xarajat» op. cit. supra n. ${ }^{\circ} 8$.

(47) E. García Gómez «Tres interesantes poemas andaluces conservados por Hill» Al-Andalus 25 (1960) pp. 307-309. 


\section{Cantos de triunfo}

No nos referimos a jarchas que forman parte del madih árabe sino de un tipo de canción estructurada de difícil análisis, pero que sospechamos que tiene un origen románico, autóctono o de importación. La existencia de estos cantos en la lírica hispánica podría probarse con el conocido texto citado por Ramón Menéndez Pidal sobre el recibimiento a Alfonso VII en Toledo por las tres etnias, cristianos, judíos y musulmanes, cada uno en su lengua (48) y cuyo posible eco tradicional podría encontarse por ejemplo en el canto colectivo del pueblo de Fuentovejuna para recibir al comendador de Ocaña en la obra de Lope de Vega. Naturalmente la jarcha más representativa de este género en la conocidísima de Yehuda Ha-Levi (no 3):

Des kand mew Sidiello bened

¡Tan bona -l-bišara!

como rayo de sol yesed

en Guadalajara.

Creemos detectar en esta jarcha unas fórmulas elocutivas entre las cuales se introduce el nombre de loado y cuyo núcleo lo constituye la comparación con el rayo de sol. De esta forma creemos que las jarchas XVII y XIX pertenecen a este género, aunque arregladas «a lo amoroso». Recordemos que ambas tienen la misma fórmula elocutiva: A rayo de Manyana, la faze de matrana con cambio de nombre del personaje y una introducción de tipo amoroso. En la versión de Emilio García Gómez:

Non dormireyo, mamma

a rayyo de manyana

Ben Abu-l-Qasim

la faze de matrana (XXVII)

Ya matre mia r-rajima

a rayyo de manyana

ben Abū-I-Haŷŷây

la faze de matrana $(X \mid X)$.

\section{Algunas conclusiones}

Ya hemos dicho que este trabajo es una aproximación a un estudio desde un punto de vista que creemos que ha quedado un tanto olvidado entre estudios excesivamente filológicos que han reducido a las jarchas a un simple aunque curioso documento lingüístico. Una primera ojeada literaria nos ha permitido observar en el horizonte nuevas posibilidades desde el punto de vista de la tipología. A la larga creemos que estudiar las jarchas como una manifestación literaria puede incluso permitir nuevos avances en su desciframiento

(48) R. Menéndez Pidal Poesía juglaresca y jugalres. Madrid, 1956 (4 ed.) p. 72. 
filológico, porque la tipología literaria presupone determinadas palabras claves y fórmulas elocutivas que hagan decir a los grafemas árabes algo más que su insegura escritura permite. El ejemplo más evidente fue la lectura del provenzalismo gilós que llevó a las jarchas al mundo de la poesía provenzal, lectura debida mucho más al conocimiento de las literaturas románica y árabe de su descubridor que a su habilidad indudable para la paleografía. 